\title{
Balancing Grace
}

\author{
Courtney J.W. Fecske \\ Indiana University Bloomington \\ coweisma@iu.edu
}

\begin{abstract}
Before banding out my midterm exam the Thursday before spring break, the unease in the classroom was palpable. I questioned, is it the right thing to do to give a midterm exam now? Two days prior we had learned that online instruction would begin the week after spring break and would continue for a week and possibly longer. This was an unprecedented scenario. I never took a seminar titled How to Continue Teaching During a Pandemic. I resolved we would get through this together, with an attitude of "let's get it done." Before passing out exams, I informally assessed students to see how many had taken an online course before; few hands rose. I then asked how everyone was feeling in regard to our inevitable online transition. Students expressed anxiety and worry because they had never taken a class titled How to Continue to Learn During a Pandemic. As we educators move abead to an uncertain culture of learning, we must strive to listen and learn, grow in our pedagogies, and balance grace and flexibility with reasonable expectations.
\end{abstract}

Keywords: remote learning, pandemic, transition, equity, pedagogy.

\section{When the Pandemic Changed Teaching: A Need for Grace Begins}

I was in my department's main office when I heard the discussion about leaving campus for spring break for 2 weeks. After rushing back to my office to read the full email, the now token word "unprecedented" began to ripple. I had a scheduled midterm in my course the next day, a full 2 days before spring break was set to begin, but the emails started to flood in: "Will the midterm be canceled?" "Will the midterm be online instead of in person?" "My parents want me to come home immediately." "I do not feel comfortable taking the exam in class," and so on. I checked with a few of my colleagues and they confirmed that they were keeping their courses largely as scheduled, since spring break did not start until Saturday and it was only Wednesday. I resolved to post an announcement on Canvas, our school's leaning management system, stating that the midterm exam would occur as planned, in class. I then responded to the many emails confirming we would have our exam as planned. For the few students not feeling well or not wanting to take the exam in our lecture hall, I offered an opportunity to take the exam outside my office independently with another proctor who had access to me if there were any exam questions. This seemed like an appropriate accommodation, affording students an adequate amount of grace during shockingly uncertain times.

On the day of the exam, the unease in the classroom was palpable. I questioned, is it the right

thing to do to give a midterm exam now? Two days prior we had learned online instruction would begin the week after spring break and would continue for a week and possibly longer. This was an unprecedented scenario. I never took a seminar titled, How to Continue Teaching During a Pandemic. I resolved we would get through this together, with an attitude of "lets get it done!" I chose to start my final face-to-face class by informally assessing the students to see how many had taken an online course; few hands were raised by the almost 100 students in the room. I then asked how everyone was feeling in regard to our inevitable online transition. Students expressed anxiety and worry because they had never taken a class titled, How to Continue to Learn During a Pandemic. While keeping in mind I had a midterm exam to proctor, I tried briefly to share that I had taught 
several online courses before, so this was not new to me, to instill a level of confidence in my ability as their instructor. Little did I know that that was a loaded statement! (Yes, I had taught many classes online before but certainly not during a public health crisis!) I even offered to create a PowerPoint presentation with tips on how to be successful in online learning and assured students I would post this advice later that same day to counterbalance this abrupt transition and provide insights on how to complete this transition seamlessly. I genuinely was not overly worried about moving our course from face-to-face to online formatting all within a period of a week or two. After all, we were already using a constructed, well-organized, module-based, easy-to-follow format on our Canvas course page.

\section{Pivoting to Remote Learning: When I Thought I Had Found Grace}

Smoothly transitioning a face-to-face course with almost 100 students, which was supposed to meet 2 days a week for 75 minutes, to an online format was the objective I set myself for spring break. Fortunately, even though my course was face-to-face, I already had the coursework integrated into Canvas. Initially, I thought to myself, this is easy, my course can easily transition to remote learningthe structure is already in place. I already had weekly modules posted, inclusive of lecture topics, assigned readings, and assigned course work. This module-based learning structure had been in place since Week 1 of the semester and provided a firm foundation for an online transition. I planned to keep lectures via the video conferencing platform Zoom synchronous but would record them and post the recorded lectures within each weekly module so students could refer back to them or watch them if unable to attend class live.

Then, as students started reaching out, the realities of inequity, access, emotional distress, and challenges adjusting to change confronted me. Deeper awareness of equity, application of inclusive practices for online learning, and balancing accountability with grace were evidently needed from myself as well as all faculty. The process of committing to promoting learning beyond the classroom while encouraging engagement online and constantly checking my privilege began. Becoming proficient with the use of tools such as Canvas (learning management system), VoiceThread (collaborative multimedia slideshow tool), Kaltura (media management system), and hybrid accessible content by trial and error became the new normal for the following 8 weeks.

While the structural online transition for my course was indeed quite simple, the realities of my students' circumstances were not. Ironically, in a course where empathy and inclusion were the main focus, I initially failed to recognize the potential problems of transitioning a course largely populated by traditional college students from an in-person on-campus learning environment to remote learning. For the 2 weeks of spring break, I had little interaction with students, as I imagine they were overwhelmed with leaving campus unexpectedly and immersing themselves in a new disruptive reality. During the "break" I used my time to record myself explaining weekly modules and assignments as well as to edit and clarify the course's written directions. I double-checked my already set weekly course modules to ensure they were clear, since students would not have easy campus access to ask questions during traditional office hours or during/after class. Interestingly, what I discovered was that this was simply not enough. Although I put in extra work to refine and modify course expectations, my students seemed to struggle with following the now explicit directions. While initially I was confident in my course transition plan, I began to feel overwhelmingly stressed out as the students' stress seeped through in emails and Zoom appointments. At this point, I needed to find a balance of grace and reasonable expectations for the remainder of the semester. 


\section{Finding Authentic Grace}

A week posttransition, feeling the weight of a wide range of emotions, I wrote on a neon yellow Post-it the word GRACE in all capital letters and stuck it on my desk. I needed the constant reminder to take a deep breath and balance grace with equitable and flexible learning. As I know now, instructors, including myself, receive little to no training and education on the impact of trauma and how it effects the teaching process (Goodwin, 2020; Keesler, 2014). Focusing on students with intellectual disabilities, Cavanaugh (2016) wrote that trauma-informed instruction "realizes the widespread impact of trauma... recognizes the signs and symptoms of trauma... responds by fully integrating knowledge about trauma into policies, procedure, and practices; and seeks to actively resist retraumatization" (p. 42). Given the unanticipated nature of a global pandemic, almost none of these practices were in place for instructors to be aware of or apply. In regard to myself and many other faculty, we are trained to be experts in our fields and not directly trained to teach. Many of us have taken measures to earn teaching certificates and participate in the copious amount of programming offered by the Center for Innovative Teaching and Learning, but I certainly had not learned about nor been trained and equipped with the tools to teach during a time of international trauma.

Having not even heard of trauma-informed instruction, I aimed to balance grace and accountability, which included problem solving, being flexible, and adjusting expectations, since anxiety was high and panic was spreading just as quickly as the pandemic. While my mind automatically returned to thinking about students' lack of adaptability, continuously reminding myself to have and show grace was essential. My classes were largely composed of late teens and early twentysomethings, many just beginning to adjust to an independent lifestyle and learning to explore their identities, and they were floundering with big life changes and quick transitions. In accordance with Goodwin (2020), trauma-informed instruction involves teachers gaining awareness of the issues within the larger environment inclusive of social influences as opposed to focusing on individual deficits. Through this macro level of understanding one can be more inclusive and apply sensitive responses to all. This specifically relates to how instructors can provide support and apply meaningful grace to students during this time. We need to be sensitive to the larger issues being experienced within our society as opposed to feeling the need to pass judgment on a case-by-case scenario, which becomes overwhelming and may cause tensions in providing grace. How many of us have received a student email only to feel unsympathetic or feel we are being put in a place of judgment that we do not want to find ourselves in? Whether we take an extra day to think about our response because our well of empathy needs to be replenished or we make a judgment call that may or may not afford the appropriate level of grace, a decision must be made, and a response must be given. How do we find and balance grace in a just way?

I sent out a check-in email to students, hoping to learn more about each student's circumstances to support their success in my course. While some students chose not to respond (which was an offered option of the check-in), I learned of a student who had left her textbook in her dorm and was afraid to go to campus while living with a father who had an autoimmune disorder. I was able to meet with this student and reached out to the textbook publisher, which graciously granted the student free online access for a limited time so she could stay up-to-date on her course readings. Next up was a student with poor connectivity; we brainstormed some options and she was able to gain internet access for free while in her car at a hotel parking lot. While not the most conventional solution, it worked. Another student only had a shared computer and was struggling to write papers on her phone; being that my course is not writing focused, I offered the option to hand write and send pictures to me or to record answers to prompts and send that, since the learning objective was the comprehension and application of course concepts. Through these

Journal of Teaching and Learning with Technology, Vol. 10, Special Issue, jotlt.indiana.edu 
accommodations, I thought I had found grace and was being reasonable in my expectations. I was proud that I was helping so many students reduce their learning constraints. As I continue to reflect, I am not so sure this was actually giving grace during trauma-perhaps I was more offering my strong problem-solving skills as a Band-Aid?

More worrisome were the students that I did not hear from, the ones that stopped participating in all course content. In an effort to support the students that seemingly vanished, I extended deadlines without penalty and eased rubric guidelines, which I now know is a humanistic pedagogy, as discussed by Mehta and Aguilera (2020). Many took advantage of this opportunity to move from failing the course to passing, but a few seemed to be unreachable. While I posted weekly announcements every Monday morning outlining what was expected for the week, I did not initially realize that some students were receiving so many electronic communications that that was a source of feeling overwhelmed as well.

Upon reflection I could have reached out more, but with a teaching load of close to 300 students, I was in the trenches and granted myself some grace to provide broad opportunities in an effort to be as supportive as I could, while still ensuring students were completing work within each course. I now acknowledge that students disappearing, not reading shared information, me receiving panicked emails, and students sending unprofessional/rude communications were likely a symptom of the larger social influences and a means of coping (Blitz, Anderson, \& Saastamoinen, 2016; Cavanaugh, 2016) and that I can in the future adjust my teaching to be more supportive, safe, collaborative, and empowering (Goodwin, 2020).

In general, students were stressed and overwhelmed even if experiencing limited equity concerns. My students living at home, with no financial concerns, not needing to work, having accessible $\mathrm{Wi}-\mathrm{Fi}$ and all the technology needed to be successful were struggling with mental wellness and time management with four or five new-to-online classes and an unexpected transition. Again, finding a way to balance an authentic sense of grace with learning during a tumultuous time is essential.

\section{Final Reflections: How Do I Balance a Sense of Authentic Grace With Regard to Reasonable Expectations?}

My students and I trudged through the semester with varying degrees of resolve. I recognize that not all of my students agreed with my decision to continue with coursework as planned but with extended deadlines and reduced assignment content, but I did what I thought was best at the time. I feel it is imperative that we all take a collective breath after the spring 2020 semester and reflect on the potential for growth as educators. Further, I realize that often inequities are hidden from faculty and that we need to take additional steps to be broadly inclusive and to reach out more on an individual level to promote a sense of connectiveness and humanness. I am in agreement with Blitz et al. (2016): "New approaches are needed to promote resiliency and student achievement by addressing the intersections of institutional bias, trauma, and the chronic stress often associated with poverty in the context of historical and structural oppression" (p. 522). I feel strongly that it is our obligation to learn how to teach through trauma and inequity to create a culturally responsive classroom (whether in person or virtual). As Blitz et al. (2016) noted, being culturally responsive includes acknowledging and validating cultural and racial identities, enhancing cultural sensitivity, being cognizant of toxic stress and its impacts, and promoting healing and growth as opposed to retraumatization. Further, Cavanaugh (2016) also spoke to the significance of acknowledging, understanding, and appreciating diversity in the classroom as a means to promote a positive and supportive learning environment. I think an initial step of finding a healthy balance of grace and empathy includes providing a place to start this process for ourselves. As noted by both Keesler 
(2014) and Goodwin (2020), within the scope of trauma-based instruction, trustworthiness, safety, choice, collaboration, and empowerment are essential to building a supportive foundation, and these were arguably, but understandably, not firmly established with the quick pivot to remote online learning in the Spring. Perhaps inadvertently through focusing on providing grace, some of these concepts were lightly applied but not enough to provide a strengths-based learning environment in a time of trauma.

Finding authentic grace and learning how to adjust my expectations versus having compassion and accepting what each student was capable of at the time was a tightrope balancing act. I choose to give myself grace and to reevaluate my own teaching values of inclusiveness, compassion, and support. In the moment, I tried to support my students' success and encourage them to push through, which felt meaningful at the time. However, I feel through doing so I did lose sight of my core values as an educator, which was problematic and a cause for pause. Since this experience of teaching at the start of the pandemic, I have taken the opportunity to increase my knowledge of pedagogies and inequities in education, enhance my understanding of flexibility and grace, learn more about trauma-based instruction, and be more prepared to do better in the future.

\section{Next Steps: Still Balancing but With Some Handrails and a Safety Net}

As faculty have moved on from the start of the pandemic and into the uncertain future, these experiences have impacted how we will continue to teach and interact with students. I chose to seize this opportunity to do better and grow as an educator. I attended as many teaching seminars and webinars as I could that I felt were relevant to my field and teaching values. I spent copious amounts of time during the summer months reevaluating each course syllabus and assignment for the upcoming fall semester. Having a better understanding of trauma and how it impacts students is imperative. The American Psychological Association (2015) stated that trauma is "an emotional response to a terrible event...and can lead to challenges with emotional regulation, social relationships, and the development of physical symptoms due to anxiety" (as quoted in Cavanaugh, 2016, p. 41). I doubt there is a single teacher at the postsecondary level or otherwise who did not become aware of students' increased stress/anxiety levels and a reduced ability to complete work during the fall 2020 semester. Now it is essential to reflect on trauma-based instruction concepts of safety, collaboration, and empowerment (Cavanaugh, 2016; Goodwin, 2020; Keesler, 2014), dig deeper into equity issues pertaining to learning and access to education, and recognize the need to continue to check in not only with our students but also with ourselves. Having just started my learning of trauma-based instruction, as I review more and more of the peer-reviewed articles and promotion of evidence-based practices for teaching, I find myself in agreement with much of what is written. I think, why did I not know this already? Should we not be fluent in the concepts of trauma-based instruction before an international trauma is upon us? Acknowledging the concept of universal trauma seems logical, especially as Cavanaugh (2016) shared that trauma is a common experience for children and can effectively inform our teaching at a macro level for a wide range of diverse students with differing experiences. If we accept trauma as a universal experience and prepare ourselves with the tools to promote strengths-based learning through trauma with the foundations of safety, trustworthiness, choice, collaboration, and empowerment (Keesler, 2014), this will equip us as educators to better teach everyone-whether there is a pandemic or more individualized trauma-based experiences.

While my neon yellow Post-it is no longer on my desk, grace is still a word that resonates for me. As I now propose collaborative course guidelines to my students and ask students what they expect/need from me, and what I should expect from them, as together we build our policies for the semester, I listen and I learn. Rooted in Freire's work on humanizing pedagogies, my approach is 
to attempt to acknowledge and account for autonomy, power, and privilege in my virtual classroom (Mehta \& Aguilera, 2020). I now ask my students, many still transitioning and adjusting to this new world of learning, how I can best reach them, and I commit to posting numerous reminders through announcements and emails weekly. As I try to be informed by humanizing pedagogies and how this translates to practice, I increase my awareness of who is excluded by each action (Mehta \& Aguilera, 2020) and I have constructed a more thoughtful and ever-evolving method of teaching online. I reevaluated all assignments and course work and genuinely thought, do they need this? Do I need this to demonstrate what has been learned? I have often thought that our education system as is could use some dusting off, so why not now? Take this unprecedented moment in the academy and rise to the challenge. I now offer an open book final exam with an option to choose to complete a cumulative worksheet instead to demonstrate learned knowledge in multiple ways based on student preference. As noted by Petre (2017), alternative assessments along with traditional assessments can enhance student motivation for learning, and instructors should be aware of promoting these options when possible. I have virtual live "coffee talks" for students to sign up for and share what they find meaningful about our learned concepts and will plan discussions and interactive activities around these topics. I am trying to promote a sense of autonomy and empowerment wherever possible in my courses. In a time where students feel they lack control over their lives, having a say in our courses and being able to make their own choices pertaining to their learning must be meaningful.

I realized that I needed to energetically promote engagement and connectivity in coconstructing a pleasant virtual community of learners. I now ask students to complete a check-in survey at the start of the semester that asks about access to technology and a workspace and to share, if comfortable, other priorities such as sibling/childcare, essential financial work commitments, and anything else students want me to be aware of as we move through the semester together. I want to secure a rapport and a sense of trustworthiness. At the time of writing, I had hopes of building a virtual classroom community that when I reflected after the fall 2020 semester, I could be proud of; I hoped to continue to grow and to know not only that I did my best in the moment, but that I was prepared and enabled my students to give their best. I feel better equipped through learning about trauma-based instruction and inequities in our institution to try to creatively and supportively begin to address these important issues. I am trying to continue to afford myself and my students grace. I must acknowledge that this is a long-term process for myself and not a quick fix and allow myself grace to work within my process. Likewise, I must continue to find grace for students even when I am feeling overwhelmed and want to push through, which is my inclination. A key component of grace is understanding and empathy. I must acknowledge that many are not privileged to be in a supportive space to enable themselves to do this or they may not know how. Part of balancing in my grace is continuing to check myself, and when my grace is off-balance, I need to take a breath and rebalance and know that I am learning along with this process and will not always respond perfectly, but as long as I continue to grow and learn each semester I will improve my balance and in turn be able to offer a more appropriate level of grace to each student. I am trying to better apply my values of inclusiveness, compassion, and equity because I know I can.

Overall, we survived the spring 2020 semester and I know that I have taken time to reflect on what this experience means as an educator and have recommitted myself to stretching my boundaries and staying true to my pedagogical values. At the start of the summer I dived into several teaching seminars, joined faculty groups to discuss equity in education, and started thinking about my own pedagogies and teaching philosophies. While I feel I could have done better, I also need to remind myself that just as my students deserve grace, so do I. I urge us all to be reflective and take advantage of this opportunity for growth and to reshape our educational practices to fit the current needs of our students. 


\section{Epilogue: Still Balancing Grace}

Since this piece was written, an entire summer and fall semester have been completed, with the current pandemic continuing and educational practices still heavily impacted. I continue to reflect on my actions in the past and have made several course adjustments based on the steps I identified above. I also firmly believe that these next steps are not a short-term fix, but more of a long-term reflective process, which I hope will enhance my teaching and change my pedagogical approaches now and in the future.

As I went through my reflective process and planned for a different fall 2020 semester, I thought about what was noted by Goodwin (2020), that "trauma-informed professional practice integrates safety, choice, collaboration, trust, and empowerment into professional practice and teaching so as not to traumatize and/or retraumatize people through actions" (p. 44). I incorporated this into the class I have described throughout this piece by constructing a collaborative syllabus with my students, which I feel was a positive interactive process for my students and myself. The very first week of the semester I held an online synchronous session where students and I discussed their expectations of me as their instructor, what I should expect from them as my students, and what guidelines our course should follow. We discussed a token system where students could request to resubmit an assignment to improve upon it or to gain an extension with no explanation needed. We discussed inequities of online learning and cameras being on and decided that it would be kindly requested but not required. We discussed that participation and engagement look different for different students and possibly most importantly, we had a candid conversation about communication. I emphasized that while students do not need to share with me their circumstances if they do not want to, that communication is essential so that I can provide support for their academic success. By starting the semester with a focus on autonomy, empathy, collaboration, and empowerment, I think I was also able to focus on creating a strengths-based learning environment where I could be deemed trustworthy and, I hope, promote a safe environment for learning to occur. Additionally, all of my courses were constructed with a clear pattern of consistency so as to support a continued sense of safety. I believe that these conversations created a rapport and common understanding between myself and my students and laid a sound foundation for grace to be given with a firm understanding of what our course learning expectations were.

I write this epilogue during winter break with another online semester ahead in spring 2021. I plan to continue many of these instructional changes and to push myself to continue to try new methods to promote a strengths-based and positive learning environment while of course becoming more comfortable balancing a genuine sense of grace. The next tangible step in my process is to continue to raise my awareness of institutionalized oppression and note what voices are not comfortably placed within my classroom. I plan to start addressing this more by increasing the representation found in course readings, authors, clinical health professional guest speakers, and case study examples that my students will use through this upcoming semester. As noted by Blitz et al. (2016) and Cavanaugh (2014), enhancing cultural responsiveness will continue to validate marginalized identities and promote the previously described basic tenets of trauma-informed instruction and strengths-based learning. For now, I continue to find my balance of grace.

\section{References}

American Psychological Association. (2015). Trauma. Internet site: www.apa.org/topics/trauma.

Blitz, L. V., Anderson, E. M., \& Saastamoinen, M. (2016). Assessing perceptions of culture and trauma in an elementary school: Informing a model of culturally responsive trauma-informed schools. Urban Review, 48, 520-542. https://doi.org/10.1007/s11256-016-0366-9 
Cavanaugh, B. (2016). Trauma-informed classrooms and schools. Beyond Behavior, 25, 41-46. https://doi.org/10.1177/107429561602500206

Goodwin, D. (2020). Trauma-informed pedagogy: Rethinking the use of graduated instructional prompts in inclusive physical education. Palaestra, 34(2), 43-48.

Keesler, J. M. (2014). A call for the integration of trauma-informed care among intellectual and development disability organizations. Journal of Policy and Practice in Intellectual Disabilities, 11, 34-42. https://doi.org/10.1111/jppi.12071

Mehta, R., \& Aguilera, E. (2020). A critical approach to humanizing pedagogies in online teaching and learning. The International Journal of Information and Learning Technology, 37(3), 109-120. https://doi.org/10.1108/IJILT-10-2019-0099

Petre, A. L. (2017). The impact of alternative assessment strategies on students. Scientific Research \& Education in the Air Force-AFASES17, 2, 157-160. http://www.afahc.ro/ro/afases/2017/22M\&H-PetreAurelianaLoredana.pdf 